\title{
Development of a mobile application to control Brucellosis and its effect in Knowledge gain among the commercial dairy farmers of Northern India
}

\author{
Arjun Prasad Verma ${ }^{1}$, Hans Ram Meena ${ }^{2}$, Diksha Patel ${ }^{3}$, Manish Sawant $^{4}$ and BS Meena ${ }^{5}$
}

Received: 22 March 2020 / Accepted: 30 June 2020 / Published online: 10 September 2020

(c) Indian Dairy Association (India) 2020

\begin{abstract}
Quick and timely dissemination of technological information from the agricultural research system to grassroots level and farmers' reaction in the form of feedback to the research system is one of the most critical inputs in technology transfer. Information and Communication Technology plays an important and crucial role where its potential can be exploited to strengthen the linkage amongst research and extension system. In this context, mobile application was developed on brucellosis prevention in dairy animals and it was tested for its effectiveness in terms of knowledge gain by the commercial dairy farmers $(n=60)$ from six district of Haryana and Punjab states. The study revealed that, the overall mean knowledge gain on Brucellosis in dairy animals through mobile application was effective $(\mathrm{p}<0.01)$ in terms of knowledge gain among the commercial dairy farmers (17.65). Pearson's correlation analysis of socio-demographic profile with knowledge gainrevealed that knowledge gain through Mobile application on brucellosis was positively and significantly correlated with education, landholding, income, herd size, milk production and experience in dairy farming at $5 \%$ level of significance. It is evident from this study that Information Communication Technologies plays significant role in knowledge gain and empowerment of dairy farmers and hence still more institutional intervention, support and innovation is required in
\end{abstract}

\footnotetext{
${ }^{1}$ Krishi Vigyan Kendra, Jhansi; Banda University of Agriculture \& Technology, Banda-210 001 (Uttar Pradesh), India

2\& 5 Dairy Extension Division, ICAR-NDRI, Karnal-132001 (Haryana), India

${ }^{3}$ Krishi Vigyan Kendra, Banda University of Agriculture \& Technology, Banda-210 001 (Uttar Pradesh), India

${ }^{4}$ Department of Veterinary and Animal Husbandry Extension, Bombay Veterinary College, (MAFSU) Parel, Mumbai -400 012, India

Arjun Prasad Verma ( $₫)$

Krishi Vigyan Kendra, Jhansi; Banda University of Agriculture \&

Technology, Banda-210 001 (Uttar Pradesh), India

Email: arjunverma45753@gmail.com
}

developing such technology transfer mechanisms in developing countries like India.

Keywords: Dairy farmer Effectiveness, Empowerment, Knowledge, Mobile Apps

\section{Introduction}

Animal husbandry is an integral component of Indian agriculture supporting livelihood of more than two-thirds of the rural population. India possesses rapid growth in animal husbandry sector to attain self-sufficiency in the production of livestock products. Livestock has considerable potential for generating additional income as well as employment through various sectors. Dairy farmers' rarely apply scientific technology for management of their farm animals. Brucellosis being one of the highly contagious ubiquitous reproductive diseases harms not only dairy animals but also pertains risk to public health and highly prevalent among bovine population of the country (Patel et al. 2014). Serological study indicates the high rate of Brucellosis on dairy farms in Haryana and Punjab with an overall herd prevalence of 65.54 per cent. It's state-wise herd prevalence was 62.79 per cent in Haryana and 72.72 per cent in Punjab (Chand and Chhabra, 2013). The livelihood security of the dairy farmers can be increased further by enhancing their access to information on brucellosis. Quick and timely dissemination of technological information on brucellosis from the livestock research system to end users and feedback to the research system are utmost importantfor the transfer of animal husbandry technology (Sasidhar and Sharma, 2006). Innovative information and communication technologies when applied to conditions in rural areas can help to improve communication, increases participation, and disseminate information and share knowledge and skills. The use of such technologies makes extension process faster, efficient and more effective. Improved communication and information access is directly related to social and economic development (Meena and Singh,2013). The growth and spread of new information and communication technology in rural India in recent years provide a viable alternative to overcome the physical barriers of faceto face inter-personal communication. Dissemination of knowledge on improved practice through appropriate delivery methods plays an important role and it can 
be multiplied manifold by modern ICT applications such as mobile application. Information provided through modern information technology gadgets should be client oriented, needbased, demand-driven, site-specific, user-friendly and should be in local language (Tiwari et al. 2010). In this context, mobile application (Brucellosis Advisor Apps) on brucellosis prevention in dairy animals was developed and its effectiveness in enhancing knowledge among the commercial dairy farmers was analysed.

\section{Materials and Methods}

The present study was carried out in six districts of Haryana and Punjab state of India. From Haryana, three different districts viz. Hisar, Sirsa and Karnal and from Punjab states, three districts viz. Ferozpur, Gurdaspur and Ludhiana were selected based on highest cattle population. From each district 20 commercial dairy farmers were selected on the basis of snowball sampling method. Total of 120 commercial dairy farmers were selected for the present study. Out of 120 respondents, 60 commercial dairy farmers were selected to assess the effectiveness of Mobile Application (Bilingual i.e. Hindi \& English) in knowledge gain on Brucellosis prevention in dairy animals. The study had followed the experimental research design i.e. Before-and-After without control design. That is the commercial dairy farmers were subjected to well-developed knowledge test in order to ascertain the pre exposure knowledge score and subsequently exposed to the mobile application on brucellosis prevention in dairy animals and then reassessed them for the gain on knowledge regarding the brucellosis in dairy animals.

\section{Statistical Analysis}

The knowledge test was developed on brucellosis and was assessed among the commercial dairy farmers through exposure to the developed mobile application. The knowledge levels of the subjects before and immediately after exposure were assessed to find out the knowledge gain on brucellosis in dairy animals. The gain in knowledge on brucellosis was taken as an indicator for the effectiveness of the mobile application in knowledge gain. The mean gain in knowledge also expressed in terms of percentage of knowledge gain. In order to test effectiveness of the developed mobile application statistically, ' $z$ ' test was applied to find out, whether there existed any significant difference between the preexposure and immediate post-exposure knowledge due to the treatment i.e. exposure to the mobile application.

\section{Results and Discussion}

\section{Development of mobile application on brucellosis prevention in dairy animals}

Mobile application was operationalized as "the act or process by which application software is developed for mobile devices which delivered as mobile application using server-side or client-side processing to provide an "application-like" experience for a mobile user. Through mobile apps subject matter content (Prevention of Brucellosis) through text and images transferred to the commercial dairy farmers. It helps to educate the user about a technology and can be stored and operated from any type of android smart phone and can be downloaded through Google play store or by sending through Shareit, Xender apps or by sending APK link through SMS which can be installed in smart phone. Once downloaded there is no need of internet to run the application. The components of mobile apps have been broadly classified in to two major parts viz. technical component and subject matter component.

\section{Technical part}

Technical component was done by Outline systems, a private firm from Chandigarh who developed the mobile application.

\section{Subject matter}

Information on Brucellosis had been taken as the subject matter (Table 1) to develop the Mobile application. In apps there were 7 components and were presented in the following table.

\section{Validation of mobile application on brucellosis prevention in dairy animals}

Validation of Mobile Application is the extent to which it reflects a specific domain of content. Expert in the concerned field were asked to rate the relevance and appropriateness of the Mobile Application on Brucellosis prevention in Dairy animals. The findings revealed (Table 3 ) that the experts were highly satisfied $(100 \%)$ with the characteristics of Mobile Application like relevancy of Application, accuracy and appropriateness of the health information, simplicity of content in enhancing knowledge on brucellosis, suitability of Mobile Application to field condition and easy in obtaining desired information on brucellosis. The experts also indicated that there was scope of improvement in certain features of the Mobile Application i.e. navigation in getting information and gestural design of application, quality of photograph used in Application (Apps), engagement of the users and aesthetic value.

\section{Socio-demographic profile of respondents}

The findings revealed (Table 4 ) that 45.83 percent of the respondents belonged to young age category that ranges up to 35 year of age. About one third (34.16\%) of the respondents had higher secondary education, an equal number of the respondents $(39.17 \%)$ were having small and large family size, majority of the respondents $(54.17 \%$ ) had medium experience ( 8 to 15 years) in commercial dairy farming. Almost half of the respondents $(44.17 \%)$ have medium land holdings followed semi-medium, large and small land-holding i.e. 27.50, 20.00 and 5.83 percent, respectively. Majority $(72.50 \%)$ of the respondents were engaged in dairy with 
crop farming. The average annual income of commercial dairy farmers was Rs. 1060000 per annum. About 41.67 percent of the respondents were rearing medium herd size (33 to 59 animals), and possess $54.74,34.74$ and 10.52 percent crossbred cow, buffalo and indigenous cow as major composition of herd size in the study area, respectively. A perusal of Table 4 revealed that 38.33 percent of the respondent's comes under low production category $(<123.92$ litres),and cent percent of the possessed and used mobile and television for obtaining information in dairying. The findings Table 1 Subject matter component of mobile application of the study are in line with the study of Obonyo and Gufu (2015) and Rathod et al. (2016).

\section{Effectiveness of mobile application in knowledge gain of commercial dairy farmers on brucellosis}

The results revealed (Table 5) that before exposure to Mobile application, mean knowledge scores was 5.38. The mean knowledge gain scores after fifteen days exposure was 23.03.

\begin{tabular}{|c|c|c|}
\hline$\overline{\text { Sl. No }}$ & Components & Content \\
\hline$\overline{1}$ & About brucellosis & $\begin{array}{l}\text { It includes information about brucellosis, alternative name, its causal } \\
\text { organism, host species and losses due to brucellosis in dairy animals. }\end{array}$ \\
\hline 2 & Mode of transmission & It covers the information through which brucellosis transmitted in other animals. \\
\hline 3 & Sign and symptoms & $\begin{array}{l}\text { It includes different types of clinical syndromes occur due to brucellosis } \\
\text { to make dairy farmers aware. }\end{array}$ \\
\hline 4 & Prevention and control & $\begin{array}{l}\text { Preventive and control measures of brucellosis to be followed by dairy } \\
\text { farmer in his or her farm for earning more profit. }\end{array}$ \\
\hline 5 & Vaccination & $\begin{array}{l}\text { It includes information on right stage of vaccination, name of vaccine, } \\
\text { source of vaccine and precaution in storage of vaccine etc. }\end{array}$ \\
\hline 6 & Ask an expert & It includes contact details of different institution for detailed information on brucellosis. \\
\hline 7 & FAQs & $\begin{array}{l}\text { Commonly asked questions along with their answers in simple language } \\
\text { were added in FAQ component. }\end{array}$ \\
\hline
\end{tabular}

Table 2 Supporting components of mobile application

\begin{tabular}{|c|c|c|}
\hline S. No & Components & Description and Uses \\
\hline$\overline{1}$ & Home & 7 components in which text in particular language along with images are present. \\
\hline 2 & Change language & $\begin{array}{l}\text { In this the farmer can change language at ease. Two languages are. } \\
\text { present in apps viz., Hindi and English }\end{array}$ \\
\hline 3 & About app & $\begin{array}{l}\text { This page reveals the importance of mobile apps to different stakeholder. } \\
\text { involved in dairying }\end{array}$ \\
\hline 4 & Team & $\begin{array}{l}\text { Names of the advisory committee member who guided the researcher in } \\
\text { development of the apps. }\end{array}$ \\
\hline 5 & Acknowledgement & $\begin{array}{l}\text { Acknowledgement is given to ICAR-NDRI, Hon. Director \& VC for } \\
\text { providing grants and guidance for development of mobile apps on } \\
\text { Brucellosis prevention in Dairy animals. }\end{array}$ \\
\hline 6 & Website link & It the address of institution for further enquiry about Brucellosis. \\
\hline 7 & Log out & $\begin{array}{l}\text { After getting knowledge regarding Brucellosis, farmer can exit the app by } \\
\text { logging out. }\end{array}$ \\
\hline
\end{tabular}

Table 3 Validation of mobile application on brucellosis prevention in dairy animals $(\mathrm{n}=30)$

\begin{tabular}{llc}
\hline S. No. & Characteristics for validation & Weighted mean score (\%) \\
\hline 1 & Relevancy of Mobile Application on Brucellosis prevention in dairy animals & 100 \\
2 & $\begin{array}{l}\text { Accuracy and appropriateness of the health information in Mobile } \\
\text { application }\end{array}$ & 100 \\
3 & Simplicity of content in enhancing knowledge on brucellosis & 100 \\
4 & Navigation in getting information and gestural design of application & 98.33 \\
5 & Quality of photograph used in Application (APK) & 98.00 \\
6 & Suitability of Mobile Application to field condition & 100 \\
7 & Easy in obtaining desired information on brucellosis & 100 \\
8 & Mobile application provide good engagement to the users & 97.22 \\
9 & Mobile application having good aesthetic value & 96.33 \\
\hline
\end{tabular}


The mean gain in knowledge scores was 17.65. In term of percentage, before exposure of Mobile application knowledge of commercial dairy farmers was 13.13 percent and after exposure of Mobile application knowledge was 56.18 percent. Overall knowledge gain among commercial dairy farmers in term of percentage was 43.05. It was also evident (Table 5) that the difference in means of pre and post-test is highly significant in term of knowledge gain on brucellosis at 0.01 levels of significance with $z$ value 19.54 and standard error of mean 0.886 . This shows that Mobile application has played a vital role in disseminating knowledge among the commercial dairy farmers. These findings were in line with Jayakumar and Manoharan (2002), Vidya et al.

Table 4 Distribution of respondents on the basis of Socio-demographic profile $(\mathrm{n}=120)$

\begin{tabular}{|c|c|c|c|c|}
\hline Sl. No. & Variables & Category & Frequency & Percentage \\
\hline \multirow[t]{3}{*}{1} & \multirow[t]{3}{*}{ Age } & Young (up to 35 years) & 55 & 45.83 \\
\hline & & Middle (36 to 50 years) & 39 & 32.50 \\
\hline & & Old (more than 50 years) & 26 & 21.67 \\
\hline \multirow[t]{5}{*}{2} & \multirow[t]{5}{*}{ Education } & Primary & 12 & 10.00 \\
\hline & & Middle & 12 & 10.00 \\
\hline & & Secondary & 26 & 21.67 \\
\hline & & Higher secondary & 41 & 34.16 \\
\hline & & Graduate and above & 29 & 24.17 \\
\hline \multirow[t]{3}{*}{3} & \multirow[t]{3}{*}{ Family Size } & Small $(<5)$ & 47 & 39.17 \\
\hline & & Medium (5 to 7$)$ & 26 & 21.66 \\
\hline & & Large $(>7)$ & 47 & 39.17 \\
\hline \multirow[t]{5}{*}{4} & \multirow[t]{5}{*}{ Land Holding } & Marginal $(<1 \mathrm{ha})$ & 3 & 2.50 \\
\hline & & Small (1 ha to $2 \mathrm{ha}$ ) & 7 & 5.83 \\
\hline & & Semi medium ( 2 ha to 4 ha) & 33 & 27.50 \\
\hline & & Medium (4 ha to 10 ha) & 53 & 44.17 \\
\hline & & Large (> 10 ha) & 24 & 20.00 \\
\hline \multirow[t]{4}{*}{5} & \multirow[t]{4}{*}{ Occupation } & Dairy Farming & 11 & 9.17 \\
\hline & & Dairy + Crop farming & 87 & 72.50 \\
\hline & & Dairy + Crop farming + Service & 13 & 10.83 \\
\hline & & Dairy + Crop farming + Business & 9 & 7.50 \\
\hline \multirow[t]{3}{*}{6} & \multirow[t]{3}{*}{ Annual Income } & Low $(<8.69$ lakhs $)$ & 57 & 47.50 \\
\hline & & Medium (8.69 to 15.36 lakhs) & 43 & 35.83 \\
\hline & & $\operatorname{High}(>15.36$ lakhs $)$ & 20 & 16.67 \\
\hline \multirow[t]{3}{*}{7} & \multirow[t]{3}{*}{ Herd Size } & Small $(<33$ animals $)$ & 47 & 39.17 \\
\hline & & Medium (33 to 59 animals) & 50 & 41.67 \\
\hline & & Large (>59 animals) & 23 & 19.16 \\
\hline \multirow[t]{3}{*}{8} & \multirow{3}{*}{$\begin{array}{l}\text { Experience in } \\
\text { commercial Dairy } \\
\text { Farming }\end{array}$} & Low experience (<8 years) & 23 & 19.17 \\
\hline & & Medium experience ( 8 to 15 years) & 65 & 54.17 \\
\hline & & High experience ( $>15$ years) & 32 & 26.66 \\
\hline \multirow[t]{3}{*}{9} & \multirow{3}{*}{$\begin{array}{l}\text { Milk Production } \\
\text { (Litre/day) }\end{array}$} & Low $(<123.92)$ & 46 & 38.33 \\
\hline & & Medium(123.92 to 232.45$)$ & 41 & 34.17 \\
\hline & & $\operatorname{High}(>232.45)$ & 33 & 27.50 \\
\hline \multirow[t]{4}{*}{10} & \multirow{4}{*}{$\begin{array}{l}\text { ICT Tools possession } \\
\text { and utilization }\end{array}$} & Radio & 76 & 63.33 \\
\hline & & Mobile & 120 & 100 \\
\hline & & Television & 120 & 100 \\
\hline & & Computer & 47 & 39.17 \\
\hline
\end{tabular}

Table 5 Knowledge Gain among respondents due to exposure of Mobile application $(\mathrm{n}=60)$

\begin{tabular}{lllllllcc}
\hline Treatment & \multicolumn{3}{c}{ Mean } & \multicolumn{2}{c}{ Mean } & Z value & $\begin{array}{c}\text { Standard } \\
\text { Error Mean }\end{array}$ \\
\cline { 2 - 6 } & $\begin{array}{l}\text { Before } \\
\text { Exposure }\end{array}$ & $\%$ & $\begin{array}{l}\text { After } \\
\text { Exposure }\end{array}$ & $\%$ & $\begin{array}{l}\text { Knowledge } \\
\text { Gain }\end{array}$ & $\%$ & & 0.886 \\
\hline $\begin{array}{l}\text { Mobile } \\
\text { Application }\end{array}$ & 5.38 & 13.13 & 23.03 & 56.18 & 17.65 & 43.05 & $19.54^{* *}$ & \\
\hline
\end{tabular}

** Significant at 0.01 level of significance 
Table 6 Correlation analysis between various factors and knowledge gain through Mobile Application $(n=60)$

\begin{tabular}{lll}
\hline S. No. & Independent variables & 'r' value \\
\hline 1. & Age & $0.101^{\mathrm{NS}}$ \\
2. & Education & $0.231^{*}$ \\
3. & Family Size & $-0.076^{\mathrm{NS}}$ \\
4. & Land holding & $0.213^{*}$ \\
5. & Occupation & $0.051^{\mathrm{NS}}$ \\
6. & Annual Income & $0.273^{*}$ \\
7. & Herd size & $0.278^{*}$ \\
8. & Milk production & $0.079^{\mathrm{NS}}$ \\
9. & Experience in commercial & $0.254^{*}$ \\
& dairy farming & \\
10. & ICT tool possession & $-0.087^{\mathrm{NS}}$ \\
\hline
\end{tabular}

(2010), and Roy and Tiwari (2014) where their respective expert system namely, Instructor Controlled Interactive Video, Educational Video-DVD on Dairy Health Management Practices, Goat Health Management Information System (GHMIS) were resulted in improvement in knowledge level after exposure. Sasikala et al. (2012) revealed significant difference with respect to mean knowledge scores and the farmers gained overall knowledge of pig farming practices about 32.56 percent. The results are in conformity with the results of Anandaraja et al. (2006), Mahmoodabad et al. (2008), Mooventhan and Philip(2012), Vanetha (2013) and Meena et al. (2014).

\section{Pearson's correlation analysis with knowledge gain due to exposure of mobile application}

The results (Table 6) revealed that knowledge gain through Mobile application on brucellosis was positively and significantly correlated with education, landholding, income, herd size, milk production and experience in dairy farming at $5 \%$ level of significance. It was not significantly correlated with variables like age, family size, occupation, milk production and ICT tools possession. The findings of Ahmed et al. (2020) contrary to study and reveals that variables age, experience, and socioeconomic status hold an insigniûcant relationship with the knowledge level of dairy farmers.In the present study, since dairy farmers had higher education level this could have made to gain in knowledge about Mobile Application on brucellosis prevention as well as size of the landholding and knowledge gain on brucellosis had positive effect due to the fact that it provides the economic base for dairy farmers to practice new technologies for achieving maximum profit. The annual income of the respondents directly influences the economic viability, stability and rational behaviour of an individual. Hence, increase in the income levels related increase access to ICT tools; this might be the reason behind the gain in knowledge regarding brucellosis through Mobile Application. Dairy farmers with large herd size are more likely to obtain information from a variety of sources. With increase in experience in dairy farming, farmers got more chance to know about different disease in their animals and it might be the reason behind the knowledge gain of the respondents on brucellosis through Mobile Application.

\section{Conclusions}

Mobile based technology dissemination was found effective among the commercial dairy farmers and it would emerge as a new paradigm in agricultural technology transfer and development of livelihood opportunities for people in the developing countries. Hence, efforts may be taken up by the extension personnel to disseminate knowledge on such aspects by using ICT tools especially mobile application to educate dairy farmers and thereby maximizing their profit. Thus, it can be concluded that mobile application not only facilitate the increased knowledge of the respondents, but also assists in the retention of the knowledge gained.

\section{Acknowledgements}

This paper forms part of the Ph.D. thesis submitted to ICARNDRI, Karnal (Deemed University) by the first author. The authors express their gratitude to Director ICAR-National Dairy Research Institute for supporting and funding the research.

\section{References}

Anandaraja N, Rathakrishnan T, Philip H (2006) Dissemination of Agricultural Technologies through Interactive Multimedia Compact Disc (IMCD): An Innovative Approach. Computers in Agriculture and Natural Resources, 4th World Congress Conference, Proceedings of the 24-26 July 2006 (Orlando, Florida USA)

Ahmed I, Kumar S, Aggarwal D (2020) Assessment of knowledge and practices of hygienic milk production among dairy farmworkers, Southwest Delhi. Indian J Community Med 45: 26-30

Chand P, Chhabra R (2013) Herd and individual animal prevalence of bovine brucellosis with associated risk factors on dairy farms in Haryana and Punjab in India. Trop Anim Health Prod 45: 13131319.

Jayakumar KA, Manoharan (2002) Effectiveness of video education among rural women. J Ext Edu 10: 2349-2350.

Mooventhan P, Philip H (2012) Impact of web-education on knowledge and symbolic adoption of farmer-an experimental study. Indian Res J Ext Edu12: 43-47

Meena BS, Kumar R, Singh A (2014) Effectiveness of multimedia digital video disk on knowledge gain of improved dairy farming practices. Indian J Dairy Sci 67: 441-445

Mahmoodabad SSM, Barkhordari A, Nabizadeh M, Ayatollahi J (2008) The effect of health education on Knowledge, Attitude and Practice (KAP) of high school students' towards brucellosis in yazd. World Appl Sci J 5: 522-524

Meena HR, Singh YP (2013) Importance of information and communication technology tools among livestock farmers: A review. Scient J Pure Appl Sci 2: 57-65

Obonyo M, Gufu WB (2015) Knowledge, Attitude and Practices towards Brucellosis among pastoral community in Kenya. Int J Innovative Res Dev 4: 375-384

Patel MD, Patel PR, Prajapati MG, Kanani AN, Tyagi KK, Fulsoundar AB (2014) Prevalence and risk factor's analysis of bovine brucellosis in 
peri-urban areas under intensive system of production in Gujarat, India. Vet World 7: 509-516

Rathod P, Chander M, Bardhan D (2016) Adoption status and influencing factors of mobile telephony in dairy sector: A study in four States of India. Agric Econ Res Rev 29: 15-26

Roy R, Tiwari R (2014) Effect of computer software on change in knowledge level of goat owners in India. Indian Res J Ext Edu 14: 27-32

Sasidhar PVK, Sharma VP (2006) Cyber livestock outreach services in India: a model framework. Livest Res Rural Dev 18: 1-12

Sasikala V, Kumaravel P, Mathialagan P, Saravanan M (2012) Effectiveness of multimedia compact disc on dissemination of knowledge among the pig farmers. Tamilnadu J Vet Anim Sci 8: 381-388
Tiwari R, Phand S, Sharma MC (2010) Status and scope of information and communication technology for livestock and poultry production in India- A review. Indian J. Anim Sci 80 : 1235-1242

Vanetha KP (2013) Effectiveness of Interactive Multimedia Compact Disc and Web Page in Knowledge Gain and Symbolic Adoption among Tribal Farm Women. Indian Res J Ext Edu 13: 85-87

Vidya P, Manivannan C, Kumar NK, Sudeep (2010) Effectiveness of an educational interactive Video-DVD on dairy health management practices in terms of knowledge gain among dairy farmers. Online $\mathrm{J}$ Rural Res Policy 5. DOI: 10.4148/ojrrp.v5i7.267 